\title{
Drug adherence for antihypertensive medications and its determinants among adult hypertensive patients attending in chronic clinics of referral hospitals in Northwest Ethiopia
}

\author{
Habtamu Sewunet Mekonnen ${ }^{1 *}$, Mignote Hailu Gebrie${ }^{1}$, Kokeb Haile Eyasu ${ }^{1}$ and Abebaw Addis Gelagay ${ }^{2}$
}

\begin{abstract}
Background: Adherence to prescribed medication is an imperative issue which can be directly linked with the management of chronic diseases like hypertension; failure to adhere can affect the effectiveness of medication as well as the efficiency of the health care system. There is scarcity of information regarding the level of drug adherence for antihypertensive medications and its determinants in Ethiopia, particularly in the study area. Therefore, the aim of this study was to assess adherence level and its determinants for antihypertensive medications among adult hypertensive patients attending the chronic illness clinics of the referral hospitals in northwest Ethiopia.
\end{abstract}

Methods: Institution based cross sectional study was conducted from March to April, 2016. The systematic random sampling technique was used to select 409 study participants from three referral hospitals. The questionnaire was prepared using the World Health Organization (WHO) conceptual model and by reviewing international literature. The data were collected using an interviewer administered questionnaire. The data were entered in to Epi - Info version 7 and then transferred to the statistical package for social science (SPSS) version 20 for data cleaning and analysis.

Bivariate analysis was first done to see the association between each independent variables and dependent variable. Variables with a P-value of less than 0.2 in the bivariate analysis were entered in to the multivariate logistic regression model for final analysis. Multivariate analysis was done using Backward logistic regression method.

$P$-value less than 0.05 was considered to determine the statistical significance of the association and odds ratio with a 95\% confidence interval was used to determine the presence, strength, and direction of association between covariates (explanatory variables) and the outcome variable. The Morisky medication adherence scale was used to assess the adherence status using $>=6$ as adherent or $<6$ as non adherent score.

(Continued on next page)

\footnotetext{
* Correspondence: habtsew@ymail.com

'Department of Medical Nursing, College of Medicine and Health Science,

University of Gondar, Gondar, Ethiopia

Full list of author information is available at the end of the article
} 
(Continued from previous page)

Results: Four hundred and nine (409) study participants were interviewed with a response rate of $100 \%$. The mean age of the respondents was 54.5 years with (Standard Deviation (SD) \pm 13.58 ). The overall rate of good adherence was $67.2 \%$ $(95 \% \mathrm{Cl}=62.8,71.6)$. Participants who had a favourable attitude towards antihypertensive medications (Adjusted odds ratio $(A O R)=9.88,95 \%$ confidence interval $(C l)$ : 5.34, 18.27), having good patient- provider relationship ( $A O R=4.25,95 \%$ $\mathrm{Cl}: 2.32,7.86)$, having one ( $\mathrm{AOR}=4.36,95 \% \mathrm{Cl}: 1.34,14.12)$ or no ( $\mathrm{AOR}=3.38,95 \% \mathrm{Cl}: 1.01,11.31)$ co-morbidities, a long duration of treatment $(\mathrm{AOR}=1.89,95 \% \mathrm{Cl}: 1.07,3.35)$, and a low medical cost $(\mathrm{AOR}=2.06,95 \% \mathrm{Cl}: 1.13,3.76)$ had associations with good drug adherence for antihypertensive medication/s.

Conclusions: The prevalence of good drug adherence for anti-hypertensive medications in this study was high. Prevention of co- morbidities, making medical services accessible, and maintaining good client-provider interaction are of paramount importance for good drug adherence.

Keywords: Antihypertensive medication, Drug adherence, Ethiopia, Hypertensive patients

\section{Background}

Hypertension, high or increased blood pressure (the systolic and diastolic level $\geq 140 / 90 \mathrm{mmHg}$ ), is a worldwide public health problem. It contributes to the burden of cardiovascular diseases, stroke, and renal failure leading to early mortality and disability [1].

Global prevalence of adult hypertensive patients was about $22 \%$ in 2014 [2]. It accounted an estimated more than $40 \%$ in African adult population [3]. In Sub Saharan Africa, it varied from $6 \%$ to $48 \%$, that is 74.7 million hypertensive individuals which will be $68 \%$ (125.5 million) by 2025 [4, 5]. In Ethiopia, it has a widely varied rate ranging from $0.8 \%$ to $31.5 \%$ [6]. The rate was $28.3 \%$ and 25.1\% for Gondar town [7] and Bahir Dar [8] respectively.

Uncontrolled hypertension is still a big medical and psychosocial problem in developed as well as developing countries. Even if the risk factors, prevention, and controlling mechanisms are well familiar, the negative outcomes resulting from the disease will possibly continue for many years. This makes the disease the biggest and most terrible social and health related challenges [9].

Hypertension (HTN) is a modifiable cardiovascular risk factor for which medications effective to regulate the raised blood pressure as well as to hamper the complications are available. But, the maximal beneficial effect of an appropriate treatment plan can be achieved only if patients strictly adhere to the recommendations. The study done by a high performance liquid chromatography tandem mass spectrometry urine analysis shows the highest prevalence of partial and total non -adherence among follow up patients with inadequate blood pressure control, and there was a linear relationship between blood pressure (BP) level and prescribed antihypertensive medications [10].

Poor adherence to antihypertensive medications is an obstacle in the management of hypertension resulting in high rate of hospitalization and death $[11,12]$. It undermines the efforts of health facilities, health professionals, and policy makers for the improvement and modification of the health of the people. Poor adherence will be the source of psychological and medical complications and has an impact on patients' quality of life, wasting health care resources and reducing individual's believe towards the health care system [13]. The study at tertiary hospital in Nigeria showed that patients with poor antihypertensive adherence had higher Sokolow-Lyon ECG (electro cardiograph) score, as well as longer P wave duration on ECG and higher rate of ECG LVH(left ventricular hypertrophy) compared to patients with good drug adherence [14].

Generally, good adherence to medications is an important achievement in disease management, and it is crucial to decrease complications like cardiovascular related morbidity and mortality $[15,16]$. However, there is a scarcity of information regarding the level of drug adherence for antihypertensive medications and its determinants in Ethiopia, particularly in the study area. Therefore, this study aimed to assess adherence status and associated factors for anti-hypertensive medications among adult hypertensive patients attending the chronic illness clinics of referral hospitals in northwest Ethiopia.

\section{Methods \\ Study design and period}

Institution based cross sectional quantitative study was conducted in northwest Ethiopia referral hospitals from March to April, 2016.

\section{Study area}

The study was conducted in referral hospitals in northwest Ethiopia, namely Debre Markos Referral Hospital at Debre Markos town, Felege Hiwot Referral Hospital at Bahir Dar city and Gondar university referral Hospital at Gondar city. Debre Markos and Gondar, which are $300 \mathrm{Km}$ and $748 \mathrm{Km}$, respectively from Addis Ababa, the capital city of Ethiopia, to the northwest are zonal cities of the Amhara National Regional state. Bahir Dar, the capital of the region, is $565 \mathrm{~km}$ from Addis. 


\section{Source and study population}

All adult hypertensive patients who were attended the chronic illness clinics of the referral hospitals in northwest Ethiopia were the source and the study population.

\section{Inclusion criteria}

Hypertensive patients aged $\geq 18$ years who have been taking antihypertensive medications at least for a month were included in the study.

\section{Exclusion criteria}

Individuals who were not capable of hearing and speaking and had known mental disorders or serious illness were excluded from the study.

\section{Sample size and sampling procedure}

The sample size was computed by using the single population proportion formula $\left(\mathrm{n}=\left[(\mathrm{Z} \alpha / 2)^{2} \times \mathrm{P} \quad(1-\mathrm{P})\right] / \mathrm{D}^{2)}\right.$ with the assumption of a $95 \%$ level of confidence, $5 \%$ margin of error, taking prevalence of adherence to antihypertensive medications as $59.5 \%$ in Adama study [17] and adding a $10 \%$ non response rate. Based on these assumptions, the final sample size was 409 . The total samples were proportionally allocated to the three referral hospitals. Study participants were selected using systematic random sampling. In each hospital, every 6 participants were interviewed based on their order of arrival.

\section{Data collection tool and procedure}

Adherence status was assessed using the Morisky medication adherence scale -8 which is a self reporting method to determine adherence. It contains eight questions with seven closed dichotomous (yes/no) answers and one liker scale question. Each item measures specific adherence behaviour. The degree of adherence was determined according to the score resulting from the sum of all the correct answers [18].

Questions regarding the explanatory variables were prepared using the $\mathrm{WHO}$ conceptual model and by reviewing international literature. The questionnaire was first developed in English and translated to Amharic, the local language, and then retranslated to English. A pre-test was administered on 21 patients at Debre Tabor Regional Hospital, northwest Ethiopia. Some amendment was made on the tool after the pre-test. In each Referral Hospital, one MSc and two trained BSc graduate nurses who were working out of the chronic illness clinics were employed for supervision and data collection, respectively. The data collection technique was a face to face interview by using a structured questionnaire. Important data like, BP were also taken by reviewing respondents' medical records or documents. After obtaining a written informed consent, the required data were collected on isolated place. To avoid the chance of recycling of data, a special mark was placed on each medical chart.

\section{Data quality assurance}

Data was controlled by using structured questionnaire which was translated to the local language, Amharic, and then translated back to English so as to see the consistency. The tool was pre-tested before use. Two days training was given for data collectors and supervisors on the tool and the procedure. Intensive supervision was carried out and data were checked for completeness and accuracy by each supervisor.

\section{Operational definition}

Adherent: respondents who scored $\geq 6$ points of the Morisky medication adherence scale - 8 [19].

Control Hypertension: maintaining the average BP reading less than $140 / 90 \mathrm{mmHg}$ at the time of data collection irrespective of measurements at other time.

Knowledgeable: when respondents scored points at mean and above $(>=6)$ for the knowledge question prepared on hypertension (HTN).

Favourable attitude: respondents who scored points at mean and above $(>=3)$ for the attitude questions prepared on HTN and its treatment were referred to be favourable.

Good patient-provider relationship: participants who scored points at mean and above $(>=6)$ for questions prepared on patient provider relationship in the treatment and care of HTN patients.

Good life style: participants who scored points at mean and above $(>=4)$ for questions prepared on life style modification in the treatment and care of HTN patients otherwise not.

Co-morbidity: the presence of any of the chronic disease along with hypertension.

\section{Data processing and analysis}

The data were checked for completeness and coded manually. After coding, it was fed to Epi info version 7. The Statistical package for social sciences (SPSS) version 20 was used for data analysis. Descriptive statistic including frequencies, means and standard deviations were calculated. Each variable was first analyzed by using bivariate logistic regression (bivariate analysis) and independent variables having P-value of less than 0.2 were entered in to multivariate logistic regression model for final analysis. Multivariate analysis was done using Backward logistic regression method. In multivariate analysis, variables with a $P$ - value of $\leq 0.05$ were considered as statistically significant. Adjusted odds ratio (AOR) was computed to see the strength and direction of the association between dependent and independent variables. 


\section{Results}

\section{Socio-demographic characteristics of the study} participants

In this study, a total of 409 study participants were interviewed with a response rate of $100 \%$. The mean age of respondents was 54.5 years with a standard deviation (SD) of \pm 13.58 . Most of the respondents, 331 (80.9\%), were Orthodox Christian by religion. Amhara ethnic groups accounted for $333(81.4 \%)$ of the total study participants. More than three-fourth $(78.2 \%)$ of the respondents were urban dwellers. Two hundred sixty one (63.8\%) reported as married, and 105 (25.7\%) were government employees. Two hundred twenty-two (54.3\%) of the respondents took less than half an hour (single trip) to reach to the hospital (Table 1).

\section{Setting, characteristics of hypertension and} antihypertensive treatments of the respondents

In this study, 246 (60.1\%) of the participants had uncontrolled blood pressure. Regarding the treatment, more than half of the participants, 234 (57.2\%), were on treatment for greater than 3 years, and 231(56.5\%) were on mono-therapy. About two- third of the participants, 267(65.3\%), had no co-morbidity (Table 2).

\section{Knowledge and attitude of respondents towards hypertension and its treatment and patient-provider relationship}

About two-third of the respondents, 258 (63.1\%), were knowledgeable and $287(70.2 \%)$ had favourable attitude towards hypertension (HTN) and its treatment. Two hundred sixty eight (65.5. \%) participants had good patient-provider relationship.

\section{Respondents' level of adherence to antihypertensive medications}

In this study, the overall prevalence of good drug adherence to antihypertensive medications was 67.2\% (95\% confidence interval $(\mathrm{CI})=62.8,71.6)$. Specifically, the prevalence of drug adherence among respondents in the three hospitals is shown in fig. 1 .

\section{Factors associated with adherence to antihypertensive medications}

The multivariate analysis revealed that having co-morbidity, duration of treatment, medical cost, attitude, and patientprovider relationship were significantly associated with adherence to antihypertensive treatment. Accordingly, study participants who had no co- morbidity were four times $(\mathrm{AOR}=4.36,95 \% \mathrm{CI}=1.34,14.11)$ more likely to adhere to antihypertensive medications than their counterparts.

Respondents who were on antihypertensive medications for three and more years were two times $(\mathrm{AOR}=$ $1.89,95 \% \mathrm{CI}=1.10,3.35)$ more likely to adhere to
Table 1 Socio-demographic Characteristic of hypertensive patients attending care in referral Hospitals in Northwest Ethiopia, 2016 ( $n=409)$

\begin{tabular}{|c|c|c|}
\hline Variable & Frequency & Percent (\%) \\
\hline \multicolumn{3}{|l|}{ Sex } \\
\hline Male & 236 & 57.7 \\
\hline Female & 173 & 42.3 \\
\hline \multicolumn{3}{|l|}{ Age } \\
\hline $18-38$ & 57 & 13.9 \\
\hline $39-59$ & 193 & 47.2 \\
\hline$>=60$ & 159 & 38.9 \\
\hline \multicolumn{3}{|l|}{ Marital status } \\
\hline Single & 39 & 9.5 \\
\hline Married & 261 & 63.8 \\
\hline Divorced & 47 & 11.5 \\
\hline Widowed & 62 & 15.2 \\
\hline \multicolumn{3}{|l|}{ Religion } \\
\hline Orthodox & 331 & 80.9 \\
\hline Muslim & 62 & 15.2 \\
\hline Protestant & 16 & 3.9 \\
\hline \multicolumn{3}{|l|}{ Ethnicity } \\
\hline Amhara & 333 & 81.4 \\
\hline Oromo & 16 & 3.9 \\
\hline Tigrie & 33 & 8.1 \\
\hline Kimant & 27 & 6.6 \\
\hline \multicolumn{3}{|l|}{ Residence } \\
\hline Urban & 320 & 78.2 \\
\hline Rural & 89 & 21.8 \\
\hline \multicolumn{3}{|l|}{ Educational status } \\
\hline Unable to read and write & 150 & 36.7 \\
\hline Able to read and write & 57 & 13.5 \\
\hline Grade $1-8$ & 66 & 16.1 \\
\hline Grade $9-12$ & 69 & 16.9 \\
\hline Above secondary school & 67 & 16.4 \\
\hline \multicolumn{3}{|l|}{ Occupational status } \\
\hline Government & 105 & 25.7 \\
\hline Merchant & 58 & 14.2 \\
\hline Farmer & 61 & 14.9 \\
\hline Housewife & 104 & 25.4 \\
\hline Non employed & 21 & 5.1 \\
\hline Retired & 50 & 12.2 \\
\hline Others $^{\mathrm{a}}$ & 10 & 2.4 \\
\hline \multicolumn{3}{|c|}{ Distance from the hospital(single trip) } \\
\hline$<=0.5 \mathrm{~h}$ & 222 & 54.3 \\
\hline$>0.5 \mathrm{~h}$ & 187 & 45.7 \\
\hline
\end{tabular}


Table 1 Socio-demographic Characteristic of hypertensive patients attending care in referral Hospitals in Northwest Ethiopia, 2016 ( $n=409)$ (Continued)

\begin{tabular}{lll}
\hline Wealth status & & \\
Poor & 130 & 31.8 \\
Medium & 156 & 38.1 \\
Rich & 123 & 30.1 \\
\hline
\end{tabular}

${ }^{a}$ Others in occupation: include daily labourer, garden, priest, NGO and private work

antihypertensive medications compared to those who were on antihypertensive medications for less than three years. Moreover, the odds of adherence to antihypertensive medications was 2 times $(\mathrm{AOR}=2.06,95 \% \mathrm{CI}=$ $1.13,3.76)$ higher in respondents who had got the medication/s free of charge or with low cost as compared to those who had got the medication/s with high cost.

Participants who had favorable attitude about antihypertensive treatment were ten times $(\mathrm{AOR}=9.88,95 \% \mathrm{CI}=$ $5.34,18.27)$ more likely to adhere to antihypertensive medications than those who had unfavorable attitude. Besides, the odds of good adherence to antihypertensive medication was 4 times $(\mathrm{AOR}=4.27,95 \% \mathrm{CI}=2.32,7.86)$ higher among respondents with good patient -provider relationship compared to poor patient- provider relationship (Table 3).

\section{Discussion}

In many developing countries, maintaining good adherence to antihypertensive medications remained the most important challenge. Adherence to antihypertensive medications contributes for controlled blood pressure and the prevention of complications.

About two-third, $67.2 \%(95 \% \mathrm{CI}=62.8,71.9)$, of the study participants had good adherence to antihypertensive medications. This finding is in-line with other studies done at Gondar University Hospital (64.6\%) [20] and in the new territories region of Hong Kong (65.1\%) [21].

However, the finding is higher than what was reported in the study done in Adama Referral Hospital (59.5\%) [17], Dar es Salaam (56\%) [22], Eastern Nigeria (52.5\%) [23], Southwest Nigeria (51\%) [24], and Hong Kong (55.1\%) [25]. This might be due to differences in sociodemographic characteristics, small sample size in Dar es Salaam and time difference. The other possible justification could be enrolment criteria and study area difference. In Hong Kong study it was in clinics where as this study is Hospital based. In addition, data collection technique in Hong Kong study was self administered but in this study it was interviewer based.

The finding is lower than the studies conducted in Maritime Canada (77.0\% [26], Pakistan(77.0\%) [27], Singapore (75.2\%) [28] and in Sunderland (79\%) [29]. This difference could be due to difference in socio-
Table 2 Setting, clinical and treatment related characteristic of respondents, Northwest Ethiopia referral hospitals, $2016(n=409)$

\begin{tabular}{lll}
\hline Variables & Frequency & Percent \\
\hline Setting/hospitals/ & & \\
Gondar university hospital & 154 & 37.7 \\
Debre Markos hospital & 67 & 16.3 \\
Felege Hiwot hospital & 188 & 46.0 \\
Blood Pressure status (systolic/diastolic) & & \\
Uncontrolled & 246 & 60.1 \\
Controlled & 163 & 39.9
\end{tabular}

Duration since diagnose of hypertension

$$
\begin{array}{lll}
<4 \text { years } & 285 & 69.7 \\
>=4 & 124 & 30.3
\end{array}
$$

Duration since starting treatment

$\begin{array}{lll}<3 \text { years } & 175 & 42.8 \\ >=3 \text { years } & 234 & 57.2\end{array}$

Number of anti hypertensive drugs:

Mono therapy

$231 \quad 56.5$

Two drugs

148

36.2

Three drugs and above

$$
30
$$

7.3

Number of tabs per day:

One

Two

$$
206
$$

50.4

Three and more

Dosage frequency:

Once daily

82

20

Two times/day

55

Three times and above

Medical cost per month(birr) for hypertension

$$
<=50
$$

$>50$

$$
235
$$

Co- morbidity

$$
\text { Yes }
$$

No

\begin{tabular}{lll} 
None & 267 & 65.3 \\
One & 120 & 29.3 \\
Two & 22 & 5.4 \\
\hline
\end{tabular}

demographic characteristics and health care facilities among this study and the comparison studies. According to $\mathrm{WHO}$, a health service is not accessible if it takes one hour and above of round trip [30]; in this study, for $45.5 \%$ of the participants it takes more than one hour to get a service which could lead to missing of appointments. Moreover, in Sunderland study participants who were taking only anti hypertensive medication for greater 


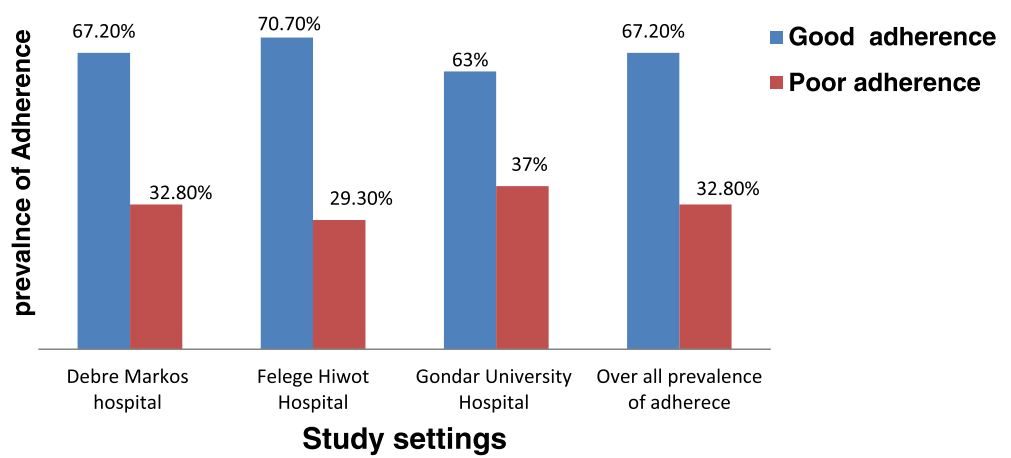

Fig. 1 Respondents level of adherence to antihypertensive medications among hypertensive patients attending care in three referral Hospitals in Northwest Ethiopia

than 6 months and merely taking antihypertensive drugs were included.

While compared to associations between outcome and explanatory variables, significant association was observed between adherence status and the number of co- morbidities was. This finding is supported by studies conducted in Adama Hospital [17], Gondar University Hospital [20], Bangladesh [31] and Hong Kong [25]. The adherence to antihypertensive medication was increased when there was no co- morbidity. The possible reason could be if there is co-morbidity, they would have pill burden and if drugs are taken orally, they may cause gastrointestinal upset. All these might cause to miss antihypertensive medications. Additionally, when patients have additional health problem, their attention might be diverted towards the newly developed disease. However, it was inversely associated in the study in Pakistan [27]. This could be due to difference in study population and early diagnosing and treatment of co- morbidities. In the Pakistan study, participants only with essential hypertension were included. But in this study, participants with any type of hypertension were included.

Duration on anti-hypertension medications had a significant association with the outcome variables in this study. The finding is similar with those of other studies in comprehensive teaching Hospital in Shanghai, China [32], Hong Kong [25], and Singapore [28]. When patients take antihypertensive medications for a long period, they would develop awareness about the complications of missing drugs and have good attitude about hypertension treatment, and these encourage patients to adhere.

This study revealed that there was a strong association between good drug adherence and respondents' attitude towards antihypertensive medications. This finding agreed with the finding of the study done in Hong Kong [25]. Having a positive attitude towards antihypertensive medications avoids misconceptions, which can cause nonadherence. People with a positive attitude may make accurate decisions and appropriate lifestyle modifications which may motivate adherence.

In this study, medical cost had a significant association with adherence to antihypertensive medications. This is comparable with the finding of a study done in Shanghai [32]. If the cost of the drug is affordable or free patients may take their medication regularly. This would help to have good adherence to antihypertensive medications.

This study noted the presence of significant association between patient- provider relationship and adherence status. The same finding was documented in studies conducted in Shanghai [32], and Southwest Nigeria [24]. Good patient-provider relationship would create a positive attitude towards treatment, and patients would have trust in the health care and the professionals. This would enhance adherence towards the recommended treatments.

In this study, difference in the level of drug adherence between urban and rural residents was not observed. The same finding was observed in a systematic review and meta-analysis [33]. A retrospective cohort study conducted in Canada also noted that there was no difference in drug adherence between urban and rural residents [34].

Though different studies have shown that blood pressure control status is significantly associated with drug adherence to antihypertensive medications [23, 35, 36], their association was not statistically significant in this study. This might be due to difference in the measurement of blood pressure control. In this study, the level of control was determined by using the single blood pressure measurement taken at the time of data collection; the other one might have used the average of two or more measurements taken on different appointment dates.

As a strength, the participants in this study were taken from different referral hospitals at different geographical areas. Thus, people who had different socio-demographic characteristics were involved. So, it gives evidence based information for Federal Minister of Health of Ethiopia and other stake holders and the information will be used to 
Table 3 Bivariate and multivariate analysis for level of adherence to antihypertensive drugs among hypertensive patients attending care in referral Hospitals in Northwest Ethiopia, $2016(n=409)$

\begin{tabular}{|c|c|c|c|c|}
\hline \multirow[t]{2}{*}{ Variables } & \multicolumn{2}{|c|}{ Adherence status } & \multirow[t]{2}{*}{$\operatorname{COR}(95 \% \mathrm{Cl})$} & \multirow[t]{2}{*}{$\mathrm{AOR}(95 \% \mathrm{Cl})$} \\
\hline & Adherent & Non adherent & & \\
\hline \multicolumn{5}{|l|}{ Age } \\
\hline $18-38$ & 37 & 20 & 1 & 1 \\
\hline $39-59$ & 125 & 68 & $0.99(0.54,1.84)$ & $0.72(0.28,1.82)$ \\
\hline$>=60$ & 113 & 46 & $1.33(0.70,2.53)$ & $0.72(2.33,2.21)$ \\
\hline \multicolumn{5}{|l|}{ Marital status } \\
\hline Single & 26 & 13 & $1.44(0.63,3.33)$ & $0.78(0.23,2.62)$ \\
\hline Married & 188 & 73 & $1.86(1.05,3.30)^{*}$ & $1.25(0.52,3.04)$ \\
\hline divorced & 25 & 22 & $0.82(0.38,1.76)$ & $0.76(0.25,2.38)$ \\
\hline Widowed & 36 & 26 & 1 & 1 \\
\hline \multicolumn{5}{|l|}{ Residence } \\
\hline Urban & 213 & 107 & 1 & 1 \\
\hline Rural & 62 & 27 & $1.15(0.69,1.92)$ & $0.69(0.35,1.39)$ \\
\hline \multicolumn{5}{|l|}{ Educational status } \\
\hline Unable to read and write & 108 & 42 & 1 & 1 \\
\hline Able to read and write & 39 & 18 & $0.84(0.43,1.63)$ & $1.27(0.45,3.58)$ \\
\hline Grade 1-8 & 34 & 32 & $0.41(0.23,0.75)^{*}$ & $0.82(0.31,2.18)$ \\
\hline Grade 9-12 & 45 & 24 & $0.73(0.40,1.34)$ & $1.52(0.52,4.46)$ \\
\hline Above secondary school & 49 & 18 & $1.06(0.55,2.02)$ & $0.75(0.16,3.43)$ \\
\hline \multicolumn{5}{|l|}{ Occupation } \\
\hline Government & 77 & 28 & 1 & 1 \\
\hline Merchant & 35 & 23 & $0.55(0.28,1.09)$ & $0.99(0.39,2.55)$ \\
\hline Farmer & 38 & 23 & $0.60(0.31,1.18)$ & $0.33(0.09,1.17)$ \\
\hline House wife & 70 & 34 & $0.75(0.41,1.36)$ & $0.87(0.37,2.04)$ \\
\hline Others & 55 & 26 & $0.77(0.41,1.45)$ & $0.5(0.21,1.18)$ \\
\hline \multicolumn{5}{|c|}{ Distance from the hospital(single trip) } \\
\hline$<=1 / 2 \mathrm{~h}$ & 150 & 72 & $1.03(0.68,1.56)$ & $0.89(0.48,1.64)$ \\
\hline$>1 / 2$ hour & 125 & 62 & 1 & 1 \\
\hline \multicolumn{5}{|l|}{ Wealth status } \\
\hline Poor & 81 & 49 & 1 & 1 \\
\hline Medium & 110 & 46 & $1.45(0.88,2.37)$ & $0.92(0.44,1.92)$ \\
\hline Rich & 84 & 39 & $1.30(0.78,2.19)$ & $1.05(0.36,3.08)$ \\
\hline \multicolumn{5}{|l|}{ Setting/Hospitals/ } \\
\hline Gondar University & 97 & 57 & 1 & 1 \\
\hline Debre Markos & 45 & 22 & $1.20(0.66,2.20)$ & $1.28(0.57,2.81)$ \\
\hline Felege Hiwot & 133 & 55 & $1.42(0.90,2.24)$ & $1.31(0.71,2.41)$ \\
\hline \multicolumn{5}{|l|}{ No of co morbidities } \\
\hline None & 180 & 87 & $2.07(0.86,4.96)$ & $4.36(1.34,14.12)^{* *}$ \\
\hline One & 84 & 36 & $2.33(0.93,5.87)$ & $3.38(1.01,11.31)^{*}$ \\
\hline Two or more & 11 & 11 & 1 & 1 \\
\hline \multicolumn{5}{|l|}{$B / P$} \\
\hline Not controlled & 163 & 83 & 1 & 1 \\
\hline Controlled & 112 & 51 & $1.12(0.73,1.71)$ & $1.07(0.55,2.06)$ \\
\hline
\end{tabular}


Table 3 Bivariate and multivariate analysis for level of adherence to antihypertensive drugs among hypertensive patients attending care in referral Hospitals in Northwest Ethiopia, $2016(n=409)$ (Continued)

\begin{tabular}{|c|c|c|c|c|}
\hline \multicolumn{5}{|c|}{ Duration since starting treatment } \\
\hline$<3$ years & 99 & 76 & 1 & 1 \\
\hline$>=3$ years & 176 & 58 & $2.33(1.53,3.55)^{*}$ & $1.89(1.1,3.35)^{* *}$ \\
\hline \multicolumn{5}{|l|}{ Antihypertensive drugs } \\
\hline One & 159 & 72 & 1 & 1 \\
\hline Two & 95 & 53 & $0.81(0.53,1.26)$ & $1.97(0.76,5.09)$ \\
\hline Three and above & 21 & 9 & $1.06(0.46,2.42)$ & $3.03(0.64,14.29)$ \\
\hline \multicolumn{5}{|l|}{ Number of tabs per day: } \\
\hline One & 150 & 56 & $1.55(0.90,2.66)$ & $2.09(0.97,4.53)$ \\
\hline Two & 73 & 48 & $0.88(0.49,1.57)$ & $1.1(0.48,2.37)$ \\
\hline Three and more & 52 & 30 & 1 & 1 \\
\hline \multicolumn{5}{|l|}{ Dosage Frequency } \\
\hline Once daily & 162 & 63 & $1.62(1.07,2.45)^{*}$ & $1.52(0.76,3.02)$ \\
\hline Twice or more & 113 & 71 & 1 & 1 \\
\hline \multicolumn{5}{|c|}{ Medical cost per month (birr) for hypertension } \\
\hline$<50$ birr & 130 & 44 & $1.83(1.12,2.82)^{*}$ & $2.06(1.13,3.76)^{* *}$ \\
\hline$>=50$ birr & 145 & 90 & 1 & 1 \\
\hline \multicolumn{5}{|l|}{ Knowledge } \\
\hline Knowledgeable & 207 & 51 & $4.95(3.18,7.72)^{*}$ & $1.45(0.78,2.7)$ \\
\hline Not Knowledgeable & 68 & 83 & 1 & 1 \\
\hline \multicolumn{5}{|l|}{ Attitude } \\
\hline Favourable & 245 & 42 & $17.89(10.57,30.28)^{*}$ & $9.88(5.34,18.27)^{* *}$ \\
\hline Unfavourable & 30 & 92 & 1 & 1 \\
\hline \multicolumn{5}{|l|}{ Pt-provider relationship } \\
\hline Good & 224 & 44 & $8.98(5.61,14.40)^{*}$ & $4.27(2.32,7.86)^{* *}$ \\
\hline Poor & 51 & 90 & 1 & 1 \\
\hline
\end{tabular}

* Variables those were significant during bivariate logistic analysis at $P$ value 0.05

** Variables that was found to have significant association during multivariate analysis at $p$ value $<0.05$

design strategies and take action to further improve level of drug adherence.

Since, patients attending their antihypertensive medications in health centers were not included in this study; this imposed a limitation on the generalization of the findings to all hypertensive patients. Since, the data was collected using interviewer administered technique, this study is prone to social desirability bias. However, the study participants were adequately informed about the relevance of this study and the importance of telling the truth. Additionally, the data collectors employed were working out of the chronic illness clinics.

\section{Conclusions}

The prevalence of good drug adherence to antihypertensive medication/s was found high. Factors like comorbidity, duration of antihypertensive treatment, medical cost, attitude towards antihypertensive medications and patient-provider relationship are important predictors of good adherence to antihypertensive medications. Prevention of co-morbidities, medical services accessibility, and having good client-provider interaction have paramount importance for good drug adherence.

\section{Abbreviations}

AOR: Adjusted odds ratio; BP: Blood pressure; $\mathrm{Cl}$ : Confidence interval; COR: Crude odds ratio; HTN: Hypertension; LVH: Left ventricular hypertrophy; MSc: Master of science; SD: Standard deviation; SPSS: Statistical package for social science; WHO: World Health Organization

\section{Acknowledgement}

Our gratitude goes to the University of Gondar College of medicine and health science school of Nursing for the approval of the ethical clearance. The authors would like to thank data collectors and supervisors for their commitment and the study participants for their valuable information.

\section{Funding}

The authors received no specific funding for this work.

\section{Availability of data and materials}

The raw data would not be provided so as to protect patients' anonymity. However, the summary data are available in the main document. 


\section{Authors' contributions}

HSM wrote the proposal, participated in data collection, analyzed the data and drafted the manuscript. MHG, KHE and AAG approved the proposal with some revisions, participated in data analysis and revised subsequent drafts of the manuscript. All authors read and approved the final manuscript.

\section{Authors' information}

HSM: A lecturer in department of Medical Nursing, College of Medicine and Health Science, University of Gondar, Ethiopia. MHG: Assistant professor of Adult Nursing in department of Medical Nursing, College of Medicine and Health Science, University of Gondar, Ethiopia. KHE: A lecturer in department of Medical Nursing, College of Medicine and Health Science, University of Gondar, Ethiopia. AAG: Lecturer in Reproductive and Child Health in Institute of Public Health, College of Medicine and Health Science, University of Gondar, Ethiopia.

\section{Competing interests}

The authors declared that we have no any competing interests.

\section{Consent to publish}

Not applicable.

\section{Ethics approval and consent to participate}

Ethical approval was obtained from University of Gondar, College of Medicine and Health Sciences, School of Nursing Ethical Review Committee, in a letter with a reference number: N/D/5029/06/08, prior to enrolment. Permission from the chronic illness follow up clinic was obtained from each medical director's office of the referral hospitals. Each study participant was informed about the purpose, method, expected benefit, and risk of the study. They were also informed about their full right not to participate or withdraw from the study at any time, and deciding not to participate had no impact on their services. Written informed consent was obtained from study participants and anonymity was employed to maintained confidentiality.

\section{Publisher's Note}

Springer Nature remains neutral with regard to jurisdictional claims in published maps and institutional affiliations.

\section{Author details}

'Department of Medical Nursing, College of Medicine and Health Science, University of Gondar, Gondar, Ethiopia. ${ }^{2}$ Institute of Public Health, College of Medicine and Health Science, University of Gondar, Gondar, Ethiopia.

\section{Received: 20 October 2016 Accepted: 30 March 2017}

\section{Published online: 05 April 2017}

\section{References}

1. WHO. World health day A global brief on hypertention. Switzerland: WHO Press; 2013.

2. Mendis S. Global status report on noncommunicable disease. Switzerland: World health organization; 2014.

3. Juliet Addo LS, Leon DA. Hypertension in Sub-Saharan Africa a systematic review. Am Heart Assoc. 2007;50:1012-8.

4. Shona Dalal JJB, Jimmy V, Clement A, Francis B, Marina Njelekela DM, Wafaie F, Walter W, Hans-Olov A, Holmes MD. Non-communicable diseases in subSaharan Africa: what we know now. Int J Epidemiol. 2011;40:885-901.

5. Ogah OS, Rayner BL. Recent advances in hypertension in sub-Saharan Africa. Heart: BMJ. 2013:99(19):1390-7.

6. Molla M. Systematic reviews of prevalence and associated factors of hypertension in Ethiopia: finding the evidence. Sci J Public Health. 2015;3(4):514-9.

7. Awoke A, Awoke T, Alemu S, Megabiaw B. Prevalence and associated factors of hypertension among adults in Gondar, Northwest Ethiopia: a community based cross-sectional study. BMC Cardiovasc Disord 2012;12:113.

8. Zelalem Alamrew Anteneh WAY, Zelalem Alamrew A, Worku Awoke Y Dereje Birhanu A. Prevalence and correlation of hypertension among adult population in Bahir Dar city, Northwest Ethiopia: a community based crosssectional study. Int J Gen Med. 2015;8:175-85.

9. Kretchy IA, Owusu-Daaku FT, Danquah SA, Asampon E. A psychosocial perspective of medication side effects, experiences, coping approaches and implications for adherence in hypertension management. Clinical Hypertension. 2015;21:19.

10. Tomaszewski M, White C, Patel P, Masca N, Damani R, Hepworth J, Saman NJ, Gupta P, Madira W, Stanley A, Williams B. High rates of non-adherence to antihypertensive treatment revealed by highperformance liquid chromatography-tandem mass spectrometry (HP LC-MS/MS) urine analysis. Heart. 2014;100(11):855-61.

11. Kimmo H, Tabák AG, Pekka M, Jussi V, Kivimäki M. Adherence to antihypertensive therapy prior to the first presentation of stroke in hypertensive adults: population-based study. Eur Heart J. 2013;34:2933-9.

12. Ong KL, Cheung BM, Man YB, Lau CP, Lam KS. Prevalence, awareness, treatment, and control of hypertension among United States adults 1999-2004. Hypertension. 2007:9(1):69-75.

13. Balkrishnan R. The importance of medication adherence in improving chronic-disease related outcomes: what we know and what we need to further know. Med Care. 2005;43(6):517-20.

14. Ebenezer Adekunle Ajayi AOA, Ajayi IA, Ajayi AO, Adeyeye VO. Adherence to antihypertensive medications and some of its clinical implications in patients seen at a tertiary hospital in Nigeria. IOSR J Dental Med Sci. 2013;8(4):36-40.

15. Donald E, Morisky S, Alfonso A, et al. Predictive validity of a medication adherence measure in an outpatient setting. Am J Med Sci. 2005;330(3):128-33.

16. Brown MT, Bussell JK. Medication adherence: WHO cares? Mayo Found Med Educ Res. 2011;86(4):304-14.

17. Habtamu Abera Hareri DMG, Bekel S. Assessment of prevalence and associated factors of adherence to antihypertensive agents among adults on follow up in Adama Referal hospital, East Shoa, Ethiopia-cross sectional study. Int J Curr Microbiol App Sci. 2014;3(1):760-70

18. DE Morisky GL, Levine DM. Concurrent and predictive validity of a selfreported measure of medication adherence. Med Care. 1986;24:67-74.

19. Menditto E, Guerriero F, Orlando V, Crola C, Di Somma C, Illario M, Morisky DE, Colao A. Self-Assessment of Adherence to Medication: A Case Study in Campania Region Community-Dwelling Population. J Aging Res. 2015;2015: 682503

20. Ambaw AD, Alemie GA, W/Yohannes SM, Mengesha ZB. Adherence to antihypertensive treatment and associated factors among patients on follow up at University of Gondar Hospital, Northwest Ethiopia. BMC Public Health. 2012:12:282.

21. Lee GK, Wang HH, Liu KQ, Cheung Y, Morisky DE, Wong MC. Determinants of Medication Adherence to Antihypertensive Medications among a Chinese Population Using Morisky Medication Adherence Scale. PLoS One. 2013;8(4):e62775.

22. Joho AA. Factors affecting treatment compliance among hypertension patients in three DISTRICT hospitals - dar es salaam. 2012.

23. Iloh GUP, Ofoedu JN, Njoku PU, Amadi AN, Godswill-Uko EU. Medication adherence and blood pressure control amongst adults with primary hypertension attending a tertiary hospital primary care clinic in Eastern Nigeria. Afr J Prim Health Care Fam Med. 2013;5(1):446

24. in Southwest Nigeria FAwTCiH, Owumi BE, Osamor PE. Factors associated with treatment compliance in hypertension in southwest Nigeria. INTERNATIONAL CENTRE FOR DIARRHOEAL DISEASE RESEARCH, BANGLADESH. 2011;29(6):619-28.

25. Kang CD, Tsang PP, Winson TL L, Harry HX W, Kirin QL L, Griffiths SM, Martin CS W. Determinants of medication adherence and blood pressure control among hypertensive patients in Hong Kong: A crosssectional study. Int J Cardiol. 2015;182:250-7.

26. Natarajan N, Putnam W, Van Aarsen K, Beverley Lawson K, Burge F. Adherence to antihypertensive medications among family practice patients with diabetes mellitus and hypertension. Can Fam Physician. 2013:59(2): e93-e100.

27. Hashmi SK, Afridi MB, Abbas K, Sajwani RA, Saleheen D, Frossard PM, Ishaq M, Ambreen A, Ahmad U. Factors Associated with Adherence to AntiHypertensive Treatment in Pakistan. PLoS One. 2007;2(3):e280.

28. Pe'ter D, Aniko C, Ma'ria M, Gyo "ngyve'r S's. Optimal recall period in assessing the adherence to antihypertensive therapy: a pilot study. Int J Clin Pharm. 2011:33:690-5.

29. Muhammad Umair Khan SS, Hameed T. Barriers to and determinants of medication adherence among hypertensive patients attended National Health Service Hospital, Sunderland. J Pharma Bioallied Sci. 2014;6(2):104-8.

30. Evans DB. Universal health coverage and universal access. Bull World Health Organ. 2013;91:546-A. 
31. Khanam MA, Lindeboom W, Koehlmoos TL, Alam DS, Niessen L, Milton AH. Hypertension: adherence to treatment in rural Bangladesh findings from a population-based study. Glob Health Action. 2014;7:25028.

32. Yue Z, Bin W, Weilin Q, Aifang Y. Effect of medication adherence on blood pressure control and risk factors for antihypertensive medication adherence. J Eval Clin Pract. 2015;21(1):166-72.

33. Murphy GK, McAlister FA, Weir DL, Lisa T, Eurich DT. Cardiovascular medication utilization and adherence among adults living in rural and urban areas: a systematic review and meta-analysis. BMC Public Health. 2014;14:544.

34. Murphy GK, McAlister FA, Eurich DT. Cardiovascular medication utilization and adherence among heart failure patients in rural and urban areas: a retrospective cohort study. CJC. 2015;31(3):341-7.

35. Hedna K, Hakkarainen KM, Gyllensten H, Jönsson AK, Andersson Sundell K, Petzold M, et al. Adherence to Antihypertensive Therapy and Elevated Blood Pressure: Should We Consider the Use of Multiple Medications? PLoS One. 2015:10(9):e0137451.

36. Azuana R, Nur Sufiza A, Thomas P. Medication adherence among hypertensive patients of primary health clinics in Malaysia. Dove Press $J$ Patient Preference Adherence. 2012:6:613-22.

\section{Submit your next manuscript to BioMed Central} and we will help you at every step:

- We accept pre-submission inquiries

- Our selector tool helps you to find the most relevant journal

- We provide round the clock customer support

- Convenient online submission

- Thorough peer review

- Inclusion in PubMed and all major indexing services

- Maximum visibility for your research

Submit your manuscript at www.biomedcentral.com/submit 